\title{
LOS PROVERBIOS GLOSADOS DE HOROZCO
}

Transcribir un manuscrito es siempre una aventura. Buscarlo durante años, dar con él y tener la buena fortuna de publicarlo es una empresa. Cuenta Jack Weiner en el prólogo cómo procuró durante años -desde 1970 según entiendo- reunirse con este manuscrito autógrafo e inédito de Horozco ${ }^{1}$. Luego se dedicó, paciente, a transcribirlo hasta en el menor detalle -calderones, crucecitas, tachaduras-, para que el lector tuviera idea clara de su estado material e incluyó seis índices que permiten hacer diversos tipos de referencias cruzadas. Hay aquí, pues, mucho trabajo, y el interesado en la paremiología tiene en dos tomos un refranero jugoso para distraer su curiosidad o estudiar su contenido.

La paremiología ha dado lugar a todo tipo de especulaciones en cuanto a lo que es y en cuanto a lo que significa; en conjunto, y por la tradición que se remonta a milenios, es parte de la historia de la cultura y de la mentalidad colectiva, pero un acervo glosado, como éste, seleccionado al azar o con propósito definido, representa el pensamiento individual. De los temas que abundan en las glosas, obtiene Weiner datos sobre la personalidad de Horozco y su opinión sobre la política, la sociedad, la religión de su tiempo: monarquista, antisemita, tradicionalista, misógino, toledano fervoroso, desconfiado de las novedades, aunque no exactamente en ese orden. De ese análisis concluye Weiner: "Horozco entonces, es en su vejez el prototipo del español inflexible, atemorizado y fosilizado siendo a la vez un autor y una persona de gran interés". Inflexible, es probable; ¿atemorizado?, quizá prudente; ¿fosilizado? Nada en sus glosas lo advierte; conservador es mejor calificativo; y melancólico también, según se denomina-

${ }^{1}$ Sebastián de Horozco, Libro de los proverbios glosados, ed. Jack Weiner, Reichenberger, Kassel, 1994, 2 ts.: 689 pp. 
ba cierto humor sombrío en el siglo xvi. Antes de comentar el primer refrán, dice Horozco que pone en sus glosas "los orígenes que se pueden alcanzar de donde cada uno de ellos provino. Y de los que no se sabe el origen pónense exemplos de lugares y partes donde se autorizan y glosan. Y los que son de Sagrada Escritura, ellos mismos se traen su auctoridad y sus verdaderos sentidos". Estas líneas anuncian su programa de trabajo: explicar los proverbios con todo lo que sabe o puede consultar en libros propios o ajenos y en la autoridad de la Vulgata que tiene a la mano.

Aparte de ese recuento temático, hay en las páginas introductorias supuestos o especulaciones curiosos. Dice Weiner que al hacer sus anotaciones trató de "descubrir y establecer fuentes que Horozco usó pero prefirió ocultarnos”. ¿Por qué querría Horozco, quien luce en todo momento su enorme acervo erudito, ocultar sus fuentes? ¿Por qué no suponer -supuesto más cuerdo si pensamos cómo se citaba en esos y en años posteriores- que simplemente no las recordaba? Por muchos datos "exactos" que se dieran (capítulos, páginas, versos, etc.) con frecuencia se citaba de memoria, de modo que no pocas veces la fuente se perdía o confundía.

Según cuenta del editor, en los proverbios se mencionan por lo menos doscientos autores. "También se puede preguntar -dice Weiner- dónde podría haber obtenido los libros que cita". Por ciertas alusiones, supone que Horozco tendría biblioteca propia en la que también habría una selección de manuscritos raros o curiosos. Buen supuesto mal rematado: "Así que Horozco mismo nos comunica que sí tenía en su posesión algunos de sus propios manuscritos $^{2}$-y me imagino que también libros impresos- y que conocía por lo menos una persona con su propia biblioteca a la cual tenía acceso". Ni "otra persona" ni "también libros impresos". Weiner tiene pruebas fehacientes de que Horozco contaba con un buen acervo; en varias glosas, cuando cita fuentes, se refiere a "mi libro" y es evidente que se refiere a un ejemplar de su colección. Pero aun así Weiner duda. En la glosa 405, por ejemplo, dice Horozco: "Este proverbio dize y alega Plutarco en su primera parte en la Vida de Solón, en nuestro vulgar, en las fojas a mi libro 271..." Weiner anota, "Este «mi libro» tampoco lo conozco". Por supuesto que lo conoce; es el ejemplar de las Vidas paralelas traducidas al español que Horozco tiene en su biblioteca.

Buena parte del prólogo es, casi verbatim, el texto de una ponencia, leída en 1992 y publicada ese mismo año, en donde Wei-

${ }^{2}$ No los suyos, sino los que adquirió, los que son de su propiedad. 
ner expone el supuesto de si esta colección de proverbios es un libro de cuentos perdido, que se enlista en tres bibliografías (siglos XVII, XVIII, XIX) entre las obras de Horozco ${ }^{3}$. Lucubra, pues, que si hay cuentos legítimos en las glosas, y si Horozco llama cuentos a ciertas glosas, por qué Tamayo de Vargas -el primer bibliógrafo que lo menciona- "no pudiera haber dado al libro de Horozco que aquí publicamos el nombre de «El libro de cuentos»" (en su notación, a veces, Weiner se refiere a una inocente glosa como "cuento"). Quien ha incursionado en la paremiología, sabe que los proverbios glosados traen cuentos, cuentecillos, anécdotas, porque son didácticos, o morales, o chistosos; afianzan la glosa o están en su lugar cuando los comentarios sobran. Así lo hace Mal Lara -de quien Horozco recibe inspiración con frecuencia- y, sin duda, Tamayo de Vargas sabía distinguir entre proverbios glosados y cuentos. Otro tema que se encuentra en la misma ponencia es la promesa de sacar alguna relación entre el Lazarillo y la posible autoría de Horozco. La conclusión sensata a la que llega, pero que no necesitaba tanta especulación, es que lo común entre las dos obras es el interés de los autores por los mismos temas.

Problema imposible de obviar y razón de muchas interrogantes que surgen en la lectura, es el español de Weiner. Podría decirse que ni las páginas introductorias ni las anotaciones están escritas en español. No quiero decir que no se entiendan (aunque a veces hay que descifrarlas), sino que a cada rato brota la lengua materna del editor. $\mathrm{Al}$ uso inmoderado de yo-innecesario en español, imprescindible en inglés- se suman frases como "no me lo pudo hacer" (en su contexto, quizá, "no me pudo informar"), "las propias experiencias que el mismo Horozco tuvo", "no me han estado disponibles", "Horozco nos descubre algo sobre lo que sería su propia librería", "pero hay uno quien le evade", "Alonso Venero... de quien muchas obras suyas inéditas han desaparecido", "Cayo Plinio Segundo es él cuyas obras han quedado", "entitulado" (de uso invariable). Y con eso basta.

Dice Weiner en el prólogo que desde que volvió de París (en 1991) se dedicó "de lleno a las anotaciones que son tantas y tan difíciles". Sin duda son difíciles y siguen siendo; hay 364 notas de pie, pero, así como muchas sobran, faltó mucho por anotar. En estos libros, siempre misteriosos, saturados de autoridades, que eran imprescindibles para sustentar, por un lado, la opinión personal, y,

3 "El libro de cuentos, 1572-1579, de Sebastián de Horozco", NRFH, 40 (1992), 233-240. 
por otro, para lucir la erudición del autor, las notas al texto deben escogerse con cuidado. ¿Para quién anotó Weiner? ¿Cómo escogió sus anotaciones? Hay notas que llama "marginales" (las apostillas al texto que pueden o no ser de Horozco, porque no sabemos si es el mismo tipo de letra), algunas extensas, otras breves (a veces una sola palabra; por ejemplo, "no”, “ojo” ). Pero no queda claro qué función tiene indicar como apostilla una pequeña cruz (aparece con frecuencia y sin patrón definido, marca, quizá, de algún interesado) sin especular, por lo menos, por qué está ahí.

Las anotaciones eruditas son muy disparejas; algunas tienen datos históricos o bibliográficos que no están al alcance de todos, pero otras están de más. Un lector más o menos instruido no necesita que lo ilustren -en dos o tres líneas- sobre Cicerón, Horacio, Heródoto, Tácito, Píndaro, y menos aún con base en el Harper's dictionary, de cuya nobleza para otros menesteres no dudo. Escojo, de manera aleatoria, algunos ejemplos:

"Plinio. Puesto que de los dos Plinios, Cayo Plinio Segundo es él cuyas obras han quedado, yo tengo que concluir que el de Horozco es éste y no su sobrino, Cayo Plinio Cecilio a quien sólo queda un discurso panegírico que dirigió al emperador Trajano. Cayo Plinio Segundo es autor de muchas obras enciclopédicas entre las cuales figura su conocidísima Historia Naturalis (Harper's Dictionary, 1965, pp. 1277-1278)". Sin mucho lucubrar, podría haber afirmado que el dato sobre uso de plumas y penachos se encuentra (y en efecto está) en la Historia Natural de Plinio el Viejo, quien estaba al tanto de esos chismes; para asegurarse, habría bastado consultar una versión anotada de la obra. En cuanto a Plinio el Joven, aparte del panegírico quedan algo más de cien cartas distribuidas en nueve libros -de las que estaba muy orgulloso, porque las publicó-, en las cuales se encuentran datos muy ilustrativos sobre la vida política, social y religiosa de su época. Prescindiendo de la Realencyclopädie der classischen Altertumswissenschaft de Pauly (magnífica, pero complicada), se puede recurrir al Oxford classical dictionary, que es accesible y tiene datos más confiables.

Dice la nota 71: "Alonso [de Cartagena] tradujo La rhetórica de Cicerón entre 1421-1422..., de la cual sólo había un códice. Pero sin duda Horozco leía el texto latino en alguna fuente puesto que La Rhetórica no se imprimió en vida de Horozco". Cicerón no escribió libros titulados Rhetorica pero sí varios sobre el tema: $D e$ inventione, Orator, De oratore, Brutus, y uno más, Ad Herennium, se le atribuyó durante siglos. ¿Cuál de ellos tradujo Cartagena? Supuse que debía ser el primero o el último, los más populares. Es de 
lamentar que la Bibliografía de la literatura hispánica de Simón Díaz no sea más explícita, pero, como es descuidada, envía a fuentes que tienen más información. La Bibliografía hispano-latina clásica de Menéndez Pelayo (t. 2, pp. 307-312), contiene los prólogos de Cartagena a su traducción, en donde se refiere a la "Retórica vieja" $(D e$ inventione) y a la "Retórica nueva" (Ad Herennium). Al final de la sección, Menéndez Pelayo explica que la traducción de Cartagena nunca entró a prensa y que "comprende sólo el primer libro $D e$ inventione".

No faltan especulaciones innecesarias, por ejemplo, a propósito de una almofadilla (almohadilla) que pide un soldado "para llevar la lançuela que me mata el hombro" (tampoco era necesario informar qué es lançuela). En el mismo proverbio, del mismo soldado "criado a sopas" Weiner se pregunta si la expresión querrá decir 'mimado'. Si el mancebo era de "agua y lana" ('de poco valor o importancia') y fue criado a sopas, sería también pobre; como se lee en Autoridades, sopa era la comida que daban "a los pobres en los conventos por ser la mayor parte de ella pan y caldo" (también "andar a la sopa" significa -según DRAE- "mendigar comida'). En esta glosa hay una frase que no tiene sentido a menos que se corrija: "Y como vía yo ya que otros mançebos de su edad se yban a Ytalia y a otras partes a la guerra..." Es probable que yo sea una errata, porque no es Horozco quien vía, sino el mancebo.

En el proverbio 375, "Cualquier tiempo pasado fue mejor", Horozco atribuye el verso a Gómez Manrique. El supuesto de Weiner: "Este libro de proverbios por Gómez Manrique me evade hasta este momento. Pues a lo mejor es un desliz de Horozco haberle atribuido este libro a Gómez y no a Jorge Manrique. En las coplas de Jorge, este no es el primero de la estrofa. Y Horozco insiste en el «primer verso» ${ }^{4}$. O aquí se ha confundido Horozco, lo cual no suele hacer, o aquí se trata de un manuscrito ya desaparecido del corregidor de Toledo. Si tal es el caso, estamos muy en deuda a Horozco por habernos indicado la existencia de este proverbiario de Gómez Manrique". No es necesario especular tanto. Dije arriba que en esos tiempos se confiaba mucho en la memoria; Horozco recordó el verso pegajoso y proverbial, cuyo tema es milenario, sin desperdicios, y lo atribuyó, sin más averiguación, al Manrique que vino primero a su memoria o al que recordaba mejor.

${ }^{4}$ No insiste; dice simplemente "Y así, Gómez Manrique, en sus Proverbios, en el primer verso..." 
El segundo tipo de notación se dedica al léxico, útil para no correr al diccionario cuando aparece algo raro. En este caso tampoco es muy claro el criterio de Weiner. Tomo ejemplos al azar. Explica "lançuela", pero deja de lado "echaqüervo" ('alcahuete' y, por extensión, 'embustero, ridículo, despreciable'), sin cuyo significado la glosa no es del todo clara. Hay palabras para las que un hablante de español no necesita explicaciones, o a veces simplemente el contexto aclara el significado: en "aqüesta", no debió tomarse el trabajo de explicar que es conjugación de "acostar", porque queda claro en su contexto ("adonde yo acostare... donde Él aqüesta"); tampoco "matriz" (iglesia matriz), "empringar", "arrancar de cuajo", "comedir", "mercar". En una lectura difícil, transcribe fifao y en su nota se pregunta si significará 'dinero'. Sí, se trata de dinero, pero del prestado, como queda claro en su contexto: "Este proverbio se puede muy bien aplicar a esta jente non sancta, los quales, para tener crédito y cumplir con el mundo procuran de se tratar de tal manera y tener tanto fiado, que todo el mundo piensa que son riquísimos". Lo mismo el "postcucos" del proverbio 269 (Cada qual con su igual): "Por esperiencia se ha visto y vee cada día que estos casamientos de moças con viejos pocas vezes salen a bien, porque o ellos en vida son cornudos, o ya que en vida no lo sean, son postcucos, porque es cosa ordinaria que como la moça viuda queda malcontenta, luego busca alguien que la contente..." Anota Weiner: "Poscucos. Esta voz no la encuentro. Podría significar 'impotentes'”. El contexto lo está diciendo claramente: se trata de cornudos póstumos.

Hay mucho más, pero basta con el proverbio 106 (De Hanete a Hayete, a tara va). Cuenta Horozco cómo cierto Hayete, hereje por añadidura, estafaba a los labradores: "Y así, en las çédulas que daba a los labradores echaba por salvado queso rallado. Y como ellos las ponían por los agujeros o en los vasares o hornillas de sus casas..., los ratones comíanse las cartas de pago al olor y sabor del queso, y él tornábales a pedir y tornaba a cobrar de ellos". Weiner anota que, en este caso, "salvado" tiene "el sentido de desmenuzado"; por supuesto que el salvado es desmenuzado,

5 Tampoco es necesario explicar qué significa "diversa conversación" (Las buenas fortunas o las honras mudan las costumbres). Explica Horozco que quien asciende en categoría "luego se hace soberbio y hinchado y de diversa conversación", palabras que, cree Weiner, "significa una manera de hablar que distancia al parlante de los circundantes". Aun sin el contexto se entiende que el favorecido habla con estilo diferente; que esa circunstancia lo distancie o no de sus interlocutores es algo que está fuera del campo semántico del adjetivo. 
pero el sentido no combina. ¿Qué tenía que hacer el salvado en una carta de pago? ¿Acaso se usaba a modo de secante en vez de la arenilla? Queda la cuestión del queso, pero no tengo fuentes para desentrañar el conundrum.

En la explicación de "a tara va" -la distancia, la categoría, entre Hanete y Hayete-, Weiner se confunde con la prosa, a veces complicada, de Horozco, quien explica que la expresión quedó "como por manera de escarnio, porque de uno a otro no iba mucho. Y qué cosa sea tara entre los que pesan ya se sabe. Y aquélla dezía el otro que avía de diferencia como quien dize mucho va de Hanete a Hayete" (yo subrayo). Aunque entre uno y otro vizcaíno no había gran diferencia, para ellos sí era de peso. El razonamiento de Weiner es peculiar, como si no hubiera leído las últimas líneas de la glosa: "A tara va. Quiere decir que hay muy poca diferencia entre los dos. 'Tara', en su sentido normal de 'peso' [¿'no?] encaja aquí. En el Diccionario de la Real Academia dice que, 'tara', significa 'tanja' bajo la quinta acepción. «Caña o palo partido longitudinalmente por medio, con encaje a los extremos, para ir marcando lo que se saca o compra de fiado, haciendo una muesca; la mitad del listón conserva el que compra y la otra el que vende; $y$ al tiempo de ajustar la cuenta las confrontan. Lo usan también las personas que no saben escribir». En este sentido, la expresión se referiría a la falta de los dos hombres de escrúpulos en los tratos comerciales". Nada de eso se encuentra en el $D R A E$, ni menos quinta acepción, ni tanja, que no aparece en ningún lado. Moliner, Casares, Autoridades y el mismo $D R A E$ sólo mencionan una caña o palo con cortes para hacer cuentas; los dos primeros dan como sinónimo tarja. Aparte del misterio del queso, queda el de la fuente que consultó Weiner.

Puesto que el conservadurismo de Horozco abarca también su léxico, un poco de historia de la lengua habría evitado especulaciones, por ejemplo, con "caxco" (111, Hazer del çielo cebolla) en donde $x$ corresponde a la prepalatal sorda š (por lo demás, no es congruente que, en la misma glosa, Horozco escribiera "el octavo çiclo estrellado" si está refiriéndose al cielo); o el arcaísmo "interrogative, afirmative" (20, Que cuidado tiene Judas de los pobres), lo mismo que inico (inicuo), en el proverbio 124. Si Weiner corrigió este vocablo, podría haber hecho lo mismo con cuchar (proverbio 79) -que aún se emplea, dice Corominas, en algunas zonas de Castilla- y con "xpiano, xpana, xpo", abreviatura común, que por regla general se transcribe "christiano", etc.

Faltan en la introducción, y es de lamentar, indicaciones precisas de los criterios que se usaron para la transcripción y notación. 
Dice Weiner que trató de transcribir el manuscrito como Horozco lo escribió y que añadió la puntuación "según el sentido del texto". Pero la explicación no es suficiente en ambos casos; en el primero, porque Weiner incluye a veces corchetes a modo de aclaración, corrección, pero no dice que resolverá abreviaturas, como sin duda lo hizo; tampoco creo que Horozco se ocupara de señalar cursivas en los títulos y en el latín, como parece en la impresión. En el segundo, porque la puntuación a veces falta, otras carece de sentido. Esos son problemas menores que el lector puede enmendar; los que no se pueden resolver son errores o erratas evidentes atribuibles, quizá, a un corrector de pruebas bastante descuidado.

En más de cuatrocientas glosas, Horozco hace gala de su conocimiento, se explaya en reflexiones cuando el tema lo merece, revela sus amarguras, sobre todo en ciertos proverbios "familiares" y, a pesar de la severidad de su prosa, a veces muestra, quizá de manera involuntaria, su peculiar sentido del humor. Está bien tener los proverbios a mano, aunque sea con las salvedades anotadas arriba y en esta impresión tan poco generosa con el contenido.

Martha Elena Venier El Colegio de México 